Revista de Indias, 1998, vol. LVIII, núm. 213

\title{
LA COMPAÑÍA ARRENDATARIA DE TABACOS Y EL MERCADO FILIPINO, 1887-1918
}

\author{
POR
}

DORIA GONZÁLEZ

Universidat Pompeu Fabra

\begin{abstract}
Cuando el Estado cedió la gestión de la administración del tabaco en España a una empresa privada y se creó la Compañía Arrendataria de Tabacos, el mercado filipino ocupaba un lugar relevante en la provisión de hoja y productos manufacturados. Sin embargo, esa modificación supuso un cambio en las reglas de juego establecidas en las transacciones con la Compañía General de Tabacos de Filipinas. En este trabajo se abordan estos diferendos y el establecimiento de la nueva política comercial que normó las relaciones entre la Compañía Arrendataria de Tabacos y la General de Tabacos de Filipinas.
\end{abstract}

Cuando en 1887 el Estado español cedió la gestión del monopolio de tabacos a una empresa privada y se creó la Compañía Arrendataria de Tabacos, la estructura de los mercados proveedores de hoja, para la confección de las labores de la Renta denotaba la importancia que había alcanzado el tabaco filipino. Precedido por el tabaco norteamericano, y seguido a distancia por el tabaco cubano, el boliche puertoriqueño y la tímida aportación de la hoja canaria, los suministros de tabaco filipino representaban entre el 30 y 33 por ciento del total de las adquisiciones anuales españolas, lo que le colocaba como el primero de los mercados tabaqueros coloniales y el segundo gran proveedor de tabaco en hoja de las fábricas peninsulares.

Lugar verdaderamente espectacular si se tiene en cuenta que el empleo de la hoja filipina era relativamente reciente, en comparación con la antiguedad del Habano, el Virginia o el Kentucky. El interés por llegar a sustituir la hoja norteamericana y el significativo aprecio que comenzó a tener el tabaco filipino en los mercados 
noeuropeos inclinaron a la Hacienda a efectuar los primeros ensayos en la fábrica de Sevilla en 1839. En aquellos primeros momentos fueron utilizadas hojas procedentes de Gapán, Cagayán y Visayas, creándose tres tipos de labores de cigarros: la MIXTA: en la que se empleaba el tabaco filipino capero y la tripa o relleno de hoja habana; la denominada ESMERADA, y la COMUN: estas últimas con empleo total de tabaco filipino pero elaboradas con diferentes hechuras.

Al mismo tiempo se comenzaron a emplear los recortes, las hojas rotas y los desperdicios en la producción de cigarrillos y picadura. La adaptación del consumo español al tabaco filipino pasó por sensibles modificaciones ya que el hábito prevaleciente era el de tabaco de clases fuertes, como el Virginia, o áspero como el Maryland, y en buena medida era el caso del Habano. Gustos que difícilmente colmaba la hoja asiática que se caracterizaba por su escaso aroma y sabor, por lo que fue necesario introducirla a través de la mezcla con el tabaco norteamericano en una oferta denominada entrefuerte en que se combinaba con el Virginia, y además, atenuando ligeramente la tradicional labor (fuerte) del Virginia y Kentucky que era la de mayor demanda, hasta conseguir ofertar una labor de picados filipinos suaves. Fue a través de estas ofertas que terminó afincándose en el consumo español el tabaco filipino. Y en 1887 los cigarros de mayor demanda popular eran los denominados marca chica y marca grande en los que se empleaba tabaco capero filipino.

El tabaco filipino se producía en la isla de Luzón y en las Visayas. En Luzón se concentraba la gran producción comercial de las provincias de La Isabela y Cagayán, que producían un tipo de hoja especialmente apreciada en España por su amplitud, lo que permitía usarlas extensamente como capas. Se clasificaban según las dimensiones y estados de las hojas en seis clases. Las clases superiores eran las caperas, y las clases inferiores específicamente la 4ta. se destinaba a la confección de picados. Estas hojas no se caracterizaban precisamente por su finura o elasticidad como podía suceder con algunas clases de tabaco norteamericano o de Sumatra, por ejemplo, pero tenían un aroma y sabor aceptable.

Seguía en importancia comercial el tabaco Igorrotes que se producía en las provincias de Ilocos Norte y Sur, La Unión, El Abra y Lepanto. Existían siete clases básicas. El Igorrotes de 1ra. y 2da. se empleaba también para capas, por las dimensiones y forma plegada de las hojas aunque se caracterizaban por un sabor amargo. Las cla-

R. I., 1998, n. $^{\circ} 213$ 
ses 3ra. y 7ma. eran de mucho uso por su parecido con el Virginia en cuanto al sabor que era muy fuerte, pero difería en su mayor densidad y escasa combustibilidad. La tipología de esta hoja permitía en ocasiones subrogar al Virginia, en especial las clases de 3ra. y 4ta., pero en general se prefería la combinación de ambas clases en un $50 \%{ }^{1}$.

El tabaco Visayas se cultivaba en las islas Panay, Negros y Cebú, era de menor calidad que los anteriores por presentar hojas muy finas, color muy pálido y escasa elasticidad lo que no favorecía su empleo en capas; no obstante, existían gradaciones, por ejemplo el de Ilo-Ilo era menos amargo y presentaba mejor combustibilidad que el Cebú o Capiz. En cambio estos últimos tenían un color más intenso y por lo general eran más gruesos.

La organización del mercado filipino de tabacos difería radicalmente de la del norteamericano, o del cubano. De cara a España las relaciones del negocio tabaquero estaban a cargo de la Compañía General de Tabacos de Filipinas que se había constituído a finales de $1881^{2}$ y centralizaba las exportaciones con ese destino. La compañía había establecido en cada región tabaquera una división por circunscripciones al frente de las cuales se encontraban agencias que adquirían el tabaco directamente de los cosecheros. Cada agencia controlaba el acopio de determinado número de haciendas. El sistema era dilatado y complejo, comenzaba según las regiones entre junio y agosto y podía extenderse hasta el mes de febrero. Se desenvolvía a través de una tupida red que comunicaba los almacenes locales con los generales que a su vez estaban vinculados a puertos intermedios desde donde el tabaco se embarcaba a Manila donde se concentraban las exportaciones.

Las modalidades del acopio variaban de una región a otra e incluso entre las propias circunscripciones, en cuanto a los criterios de clasificación, grados de preparación de la hoja y embalaje. En la

\footnotetext{
1 Santos y Campoy, Nociones Generales del Tabaco, citado por E. Delgado MARTín, La Renta del tabaco, Madrid, 1892, pp. 68-69 y 76-77.

2 La Compañía General de Tabacos de Filipinas se estableció formalmente como sociedad anónima el 26 de noviembre de 1881, cuando comparecieron a este fin ante el notario de Barcelona D. Luis G. Soler y Pla, Antonio López y López, por sí, Isidoro Pons y Roura, como representante del Banco Hispano Colonial y apoderado de la Banque de Paris et des Pays Bas, y José Carreras y Xuriach como apoderado de la Sociedad General de Crédito Mobiliario Español. Ver Emili GiRAl Reventos, La Compañía General de Tabacos de Filipinas, 1881-1981, Barcelona, 1981.
} 
Isabela los cosecheros entregaban el tabaco en los almacenes de la Compañía, previamente clasificado en fardos compuestos de 40 manos, que tenía cada uno 100 hojas. En el almacén se volvía a clasificar dividiéndose en cinco clases y se formaban las mándalas donde sufría una fermentación y luego era empacado para su traslado al puerto intermedio de Lal-loc. En los almacenes de este puerto se realizaba otra clasificación y se reembarcaba a Manila, donde nuevamente era clasificado y reenvasado para la exportación.

En Cagayán el proceso de acopio era distinto, los agricultores entregaban el tabaco en ranchos ubicados en las localidades próximas a las haciendas, donde se clasificaba y luego se transportaba al almacén correspondiente. El Igorrotes se entregaba por peso y el puerto intermedio de embarque era el del pequeño poblado de Carlatan. El acopio del Visayas estaba organizado a través de dos casas, establecida una en Ilo-Ilo, isla de Panay y la otra en Cebú. Este tabaco también se entregaba por peso directamente en los almacenes centrales de las respectivas islas desde donde era trasladado a Manila ${ }^{3}$.

En España el sistema tradicional para la adquisición del tabaco en rama era el de la adjudicación del servicio en concurso público a un contratista, el cual quedaba obligado por vínculo de derecho a cumplir un Pliego de Condiciones estipuladas por la Administración. Por interés de ambas partes estos conciertos eran de larga duración. Teóricamente la obligación contractual a que se sometía el contratista garantizaba a la Hacienda obtener por un período, en ocasiones, no menor de cinco años, la provisión de las clases de hojas necesarias a precios remunerativos para el mantenimiento de la producción. El contratista a su vez, eludía los riesgosos cambios del mercado, lo que le permitía hacer propuestas ventajosas y obtener considerables márgenes de beneficios a través de la suplantación de las clases concertadas por otras de calidades inferiores. A la sombra de este sistema se consolidaron importantes patrimonios como fueron, por mencionar tal vez los más espectaculares, los casos de Salamanca y el Marqués de Campo 4 .

\footnotetext{
3 Ibidem, pp. 47-50.

4 Sobre el Marqués de Campo, Francesc Almela I Vives, El Marqués de Campo, capdavanter de la burguesía valenciana (1814-1889), Valencia, Ajuntament Valencia, 1989. Telesforo M. HERNÁNDEZ SEMPERE, Ferrocarriles y capitalismo en el País Valenciano 1843-1879, Valencia, Ayuntamiento de Valencia, 1983.
}

R. I., $1998, \mathrm{n}^{\circ} 213$ 
Al mercado filipino se accedía a través de contratos con la Compañía General de Tabacos Filipinos, que desde 1882 concertaba con la Hacienda el suministro de esta hoja, también desde una posición privilegiada. Quiere esto decir que al crearse la Compañía Arrendataria de Tabacos en 1887, existía un entresijo de fuertes intereses, ya fuera la Compañía de Tabacos de Filipinas, ya fueran grupos comerciales, como el que podía representar el Marqués de Campo, o de carácter estatal, en el caso de Canarias, que representaban y ejercían cada uno y en diverso grado el ejercicio de unas determinadas reglas de juego en la esfera de directa competencia de la Arrendataria y justamente en uno de los ámbitos de mayor sensibilidad: la adquisición de la materia prima. Reglas del juego que tendrían que sufrir inevitablemente una modificación con la creación de la nueva entidad, y que desde luego implicaron un reajuste de fuerzas y normas comerciales, reajuste que se tradujo en sucesivas crisis, fricciones, negociaciones y pactos. Ninguna otra esfera de actividad brindó un campo tan extenso al despliegue de la competitividad como el diferendo entre la CAT y estos círculos de intereses tabaqueros por conseguir establecer mecanismos mutuamente ventajosos en el ámbito de mayor sensibilidad del sistema productivo o sea el de la materia prima.

\section{LAS RELACIONES ENTRE LA CAT Y LA CGTF.}

Cuando en 1887 la empresa se hizo cargo de los contratos de adquisición de materia prima establecidos por la Hacienda, se evidenció la precaria situación en que se encontraba el abastecimiento de hoja. Lo primero que sucedió fue que la CAT no recibió del Estado tabacos filipinos en cantidad suficiente para mantener la producción en los niveles requeridos; lo segundo, fue la constatación del incierto cumplimiento en que gravitaban los contratos firmados. Un primer balance efectuado en el mes de junio de 1887 calificaba de considerables los débitos de los contratistas, y era previsible que no se pudiera acopiar la hoja en el tiempo oportuno para impedir la paralización de algunos talleres. La situación se agravaba porque se encontraba retrasada la subasta y adjudicación de la hoja filipina que debía proporcionar capas, de las que apenas existían provisiones para un mes. Ante esta emergencia la gerencia de la Arrendataria instó al contratista fili- 
pino para que anticipara las primeras entregas, al tiempo que exigió a los que tenían débitos pendientes que los solventaran.

Aunque las existencias de hojas habanas y virginia estaban garantizadas hasta febrero del siguiente año, la preocupación de que se pudiera llegar a extender la crisis les llevó a negociar inmediatamente con el Marqués de Campo la adquisición de 4.000 tercios de tabaco habano ${ }^{5}$. Como consecuencia de esta situación el 14 de julio la dirección adoptó la medida de suspender las labores ${ }^{6}$ de Conchas y Regalías?.

Es obvio que la empresa no estaba en condiciones de permitirse reiteradas crisis de esta envergadura, por lo que en el primer informe del presidente al consejo de administración, éste recomendó la conveniencia de que se hiciesen algunas compras directas en los mercados. Con relación al mercado filipino la situación era compleja y la implantación de nuevas normas comerciales estuvieron precedidas, de fuertes fricciones.

Desde finales de 1888 se recibían noticias en la CAT de que se estaba adquiriendo esta hoja a un precio muy elevado, lo que motivó que se creara en los primeros meses de 1889 una comisión especial para que informara documentadamente al consejo de administración sobre el estado de existencias en almacenes, las fechas oportunas para las compras, el precio del contrato vigente, los precios en el mercado y que efectuase proposiciones sobre "..el modo de proveerse con la mayor ventaja posible de las clases de hoja que nuestras fábricas necesitan".

La propuesta de la CGTF era de 2.05 pesetas el kilogramo. Si el contrato era por un año se rebajaba a $2.00 \mathrm{ptas} / \mathrm{kg}$ y si era por seis meses se subía el precio a $2.25 \mathrm{ptas} / \mathrm{kg}$, lo que fue rechazado por la CAT. Con el objetivo de aclarar la situación real del mercado filipino se decidió enviar con toda urgencia un agente a Manila. En muy pocas semanas se recibía en Madrid la noticia de que existían unos 20.000 quintales de tabaco en manos de comerciantes y los precios

5 Compañía ARRendataria de tabacos, Actas del Consejo de Administración, sesión de 29 de septiembre de 1887.

6 En la terminología tabaquera se denomina labor a cada uno de los productos que se confeccionan en las fábricas de tabacos. Ver José M. RoDRíGUEZ GoRDILLO, Diccionario Histórico del Tabaco, Madrid, CETARSA, 1993, p.130.

7 Disposición ratificada por Real Orden de 27 de julio de 1887.

R. I., $1998, \mathrm{n}^{\circ} 213$ 
corrientes eran muy inferiores a los propuestos por la CGTF, e incluso muy inferiores a los que estaban concertados en el contrato.

Lo primero que se constató fue que el mercado filipino era un mercado abierto, donde si bien la CGTF tenía un peso significativo, no monopolizaba la comercialización. Incluso se llegó a asegurar que no producía ni controlaba, como se creía, el tabaco de Cagayán y de la Isabela. Ante estas noticias la CAT dio ordenes de compra al Sr. Ortiz Vega, siendo estas las primeras adquisiciones directas de tabaco filipino al margen de la CGTF.

Fue éste el marco en el que se desataron las fricciones comerciales entre la CAT y la CGTF. En el momento que se tuvo noticias en Manila que la CAT había iniciado la compra de algunos cientos de quintales de tabaco Isabela, la CGTF comenzó a adquirir de segunda mano "...cuanto se presentaba casi a como se lo pedían,...sin reparar en precios"8, lo que provocó un alza inmediata de los precios corrientes de algunas calidades. Ante ello la CAT decidió continuar adquiriendo el tabaco aún a los tipos elevados, pero era evidente que esta situación no podía dilatarse por mucho tiempo, y que debía replantearse el marco normativo de las relaciones con la CGTF.

No escapaba a la CAT el hecho de que la subida artificial de los precios era coyuntural y lo esencial radicaba en que el tabaco filipino se podía adquirir directamente en condiciones más favorables que las de los contratos pactados tradicionalmente con la CGTF. Luego de realizar un balance de las existencias y aprobar las compras directas en Manila, se estudió la posibilidad de adquirir la hoja en Europa y en último extremo subrogarla con otras procedencias. Una serie de acuerdos adoptados por el Consejo de Administración marcaban la posición de la Arrendataria con relación a la CGTF: 1) Que dados los precios corrientes en el mercado, no eran admisibles las proposiciones de la Compañía General de Filipinas. 2) Que como sistema de adquisición, y a propuesta de la Comisión, se estimaba preferible el sistema de compra directa y para ello se debían establecer en Manila y en los principales puntos productores Factorías de la CAT o agentes ${ }^{9}$.

\footnotetext{
8 CAT. Actas del Consejo de Administración, sesión del 20 de abril de 1889. Vol. III.

9 CAT. Actas del Consejo de Administración. Informe de la Comisión Especial sobre el mercado Filipino. Madrid, 20 de abril de 1889, sesión de 20 de abril de 1889. Vol. III.
} 
La reacción por parte de la CGTF no se hizo esperar, a los pocos días se recibía una carta de su director manifestando "que se debían considerar rotas las relaciones oficiales entre ambas sociedades a virtud del envío de un agente (de la CAT) a Manila" y advertía "..que se halla en el deber de lanzarse resueltamente a la defensa de sus intereses, empleando cuantos medios estén a su alcance e imponiéndose los sacrificios que sus recursos le permitan para desalojar de su campo de acción a los que vengan a producirle aquel trastorno"10. La respuesta de la CAT fue mesurada, "el arriesgarse en competencias no motivadas y el considerar más pronto o más tarde y sin razón rotas las relaciones entre las dos Compañías corresponde a la de Filipinas, pues la Arrendataria ni las provoca, ni las desea, ni las teme y hoy, como ayer, insiste en desear para ambas la mayor cordialidad de relaciones, sin que se entienda que ni estas benevolencias, ni las arrogancias de la carta de que se ha hecho mérito debilitarán sus tranquilas decisiones"11. En realidad la CAT ya tenía formada una opinión de la política a seguir en el diferendo con la CGTF. En este sentido, se plantearon dos planos de acción, uno inmediato para la adquisición de la cosecha en curso; el siguiente, la adquisición regular a largo plazo.

La situación inmediata de la CAT era difícil porque la mayor parte del tabaco estaba acaparado por la CGTF, con lo cual se ratificaba el acierto de las medidas adoptadas inicialmente. Sin embargo las expectativas para los años sucesivos eran más alentadoras tal y como se presentaba la capacidad competitiva de una y otra entidad. La superioridad de la CGTF sobre la CAT se apreciaba sobre todo en la antigüedad de su organización en aquel mercado, pero esa ventaja desaparecería desde el instante en que la CAT organizara allí sus servicios, estimándose que para ello bastaba el plazo de un año.

Dos hechos estaban claros para la CAT: 1) El precio establecido en el contrato con la CGTF era de dos pesetas cinco céntimos el kilogramo de tabaco y este se podía obtener y de hecho se adquirió por el agente de compras a menos de una peseta 50 céntimos. 2) De los 300.000 quintales de tabaco que se producían en Filipinas, España consumía aproximadamente la mitad, lo que colocaba a la Arrendataria en una posición de exigencia razonable. Una postura intran-

10 CAT. Actas del Consejo de Administración, sesión de 10 de mayo de 1889.

11 CAT. Actas del Consejo de Administración, sesión del 10 de mayo de 1889.

R. I., 1998, n. $^{\circ} 213$ 
sigente por parte de la CGTF no podía ser perdurable entendiéndola desde su posición de productora, fabricante y comerciante.

Como productora la CGTF había realizado en estos años importantes inversiones de capitales pero aún los resultados eran inciertos; en este sentido una política desde la CAT que elevara los precios de la hoja en Filipinas estimularía el fomento del cultivo y a la larga se deprimirían el valor de la hoja lo que terminaría perjudicando a la CGTF. En cuanto a su condición de fabricante, también le afectaría sensiblemente que la CAT provocara un alza de precios en las clases caperas, porque aunque algo ganaría como productora, esto no le compensaría en la fabricación donde empleaba estas calidades. Una última probabilidad era que llegase a acaparar las clases inferiores, pero tampoco sería una política eficaz ya que solo se consumían en España y se podía ejercer la ley para que permaneciera ese tabaco estancado en sus almacenes y desde luego, inmovilizado el capital que hubiera destinado a estas compras.

De acuerdo con las informaciones de que disponía la CAT no era presumible que la CGTF tuviera capacidad para acaparar en un tiempo breve los 300.000 quintales que se producían en Filipinas, mucho menos que se arriesgase a provocar el establecimiento de una nueva línea de vapores entre aquellas islas y España, en detrimento de la Trasatlántica. Todos estos argumentos se debatieron exhaustivamente en los consejos y comisiones creadas al efecto; la propuesta de crear en Manila una Administración Principal con las Factorías correspondientes, aunque aprobada, no se había llevado a efecto en el entendido de que la CGTF iba a procurar evitar la lucha comercial, pero en vista de la ruptura anunciada por su director el asunto entraba en una nueva fase.

En este sentido se entendió que debían ampliarse las atribuciones de la Representación establecida en Manila, porque no bastaba ya un agente de información cuando de lo que se trataba era de organizar y perfeccionar la administración, y era indispensable hacerlo rápidamente, porque corría mayo y el acopio de los tabacos de Luzón empezaban en el mes de agosto, que aunque continuaba hasta fin de año e incluso podían extenderse hasta febrero, las primeras partidas llegaban a Manila en octubre. El tabaco de Visayas se acopiaba entre junio y agosto, y ya estaría localizado en los puertos en el mes de septiembre.

Se designó entonces a un funcionario de toda confianza de la CAT como Jefe de la Representación en Manila, el Sr. Juan de la 
Cruz Ruiz de Castañeda con las siguientes facultades: 1) La de organizar los servicios y nombrar los agentes necesarios. (agentes que estarían comprendidos en la plantilla que luego aprobaría el Consejo). 2) La de comprar, en vistas de las circunstancias del mercado, las cantidades y clases de hoja que le fijara la dirección, bien a través de concursos o por compras directas. 3) Ordenar todos los pagos. 4) Dar periódicamente informes sobre el mercado y proponer cuanta sugerencia fuese factible a los intereses de la CAT.

Con esta Representación iría un Interventor que tendría a su cargo la fiscalización de los contratos que se concertasen y de todas las operaciones que se consumaran ${ }^{12}$. Ante la determinación de la CAT de intervenir con todas sus consecuencias en el mercado filipino, la CGTF cedió y en menos de quince días se recibía en Madrid una carta del Sr. Miralles ${ }^{13}$ en términos conciliatorios. Carta que estuvo precedida de una serie de conferencias entre el Presidente de la CAT, Manuel Vázquez Queipo y y el Marqués de Comillas. Presentaba ahora la CGTF nuevas proposiciones para el suministro de tres y cinco años respectivamente, señalando como precio en el primer caso el de una peseta 90 céntimos, y en el segundo de una peseta 80 céntimos por kilogramo. La reducción de precios propuesta por la CGTF implicaba un ahorro de más de dos millones de pesetas, con relación al precio vigente del contrato. En este caso el Marqués de Comillas ofrecía hacer una rebaja en los precios si se aceptaban para el suministro las cantidades señaladas por el Sr. Miralles y se concedía a la CGTF el derecho de entregar un $30 \%$ más o menos de año a año para aprovechar las mejores condiciones de las cosechas, “..pero confiándose en todo caso...a la lealtad de la Compañía Arrendataria y subordinando aquel derecho a las necesidades de ésta, con lo cual el precio resultará de una peseta 75 céntimos"14.

12 Esta fue una decisión muy discutida y aprobada por mayoría, con los votos en contra de los consejeros Angolotti y Luque que manifestaron sus reservas de entrar en una lucha abierta con la CGTF porque pensaban que los gastos que ocasionaría establecer una Administración en Manila no estarían suficientemente compensados con las diferencias en los precios. CAT. Actas del Consejo de Administración, sesión de 10 de mayo de 1889. Vol. III.

13 La carta del Sr. Miralles, Director de la CGTF, estuvo precedida de una serie de conferencias entre el presidente de la CAT, Manuel Vázquez Queipo y el Marqués de Comillas en su carácter de Presidente de la CGTF, a petición de este último, y con la mediación del Sr. Luque.

14 CAT. Actas del Consejo de Administración, sesión del 27 de mayo de 1889. Vol. III.

R. I., 1998, n. $^{\circ} 213$ 
Esta era una consideración muy importante si se tiene en cuenta que eran los primeros años de la CAT en los que tenía mayores dificultades para obtener el canon y el interés correspondiente al capital invertido en el negocio. No obstante, se fijaron en el debate dos posiciones, una que insistía en la necesidad de dilatar las negociaciones hasta obtener una rebaja aún mayor de los precios señalados y por un plazo de dos años. La otra, estimaba aceptables las proposiciones de la CGTF, y se inclinaban por la que se refería a un plazo de cinco años. O sea, de lo que se trataba era de llegar a un acuerdo de adquisición en un plazo corto con precios elevados en principio y a negociar una rebaja aceptable, o llegar a un pacto que considerase un plazo largo con precios más bajos, y en este caso aceptando sin modificar una de las propuestas presentadas, que fue la que tras una larga discusión se adoptó por mayoría ${ }^{15}$.

Luego de dilatadas negociaciones se redactó un proyecto de Pliego de Condiciones, basado en el general de Hacienda y la CGTF terminó aceptando como fórmula conciliadora que "reconocía en la Arrendataria el derecho de enviar al Archipiélago los Comisionados que estime convenientes; pero confía la lealtad de esta, y espera que continuarán las buenas relaciones de ambas sociedades contratantes, evitando la perturbación del mercado y el alza de los precios". Quedando de esta forma establecida la fórmula de adquisición de tabaco filipino a través de un convenio con la CGTF a largo plazo, modelo que con escasas variaciones siguió aplicándose en el siglo XX.

EL MERCADO DE TABACO FILIPINO EN LA CRISIS FINISECULAR: ESTRATEGIAS Y RESULTADO.

En el último lustro del siglo XIX ocurrieron modificaciones importantes en el sistema de adquisiciones del tabaco en rama de la Compañía. En la primera mitad del decenio de 1890 el cambio consistió en hacer extensivo a todos los mercados el sistema de contratos de larga duración, tomando como modelo el convenio firmado en el año de 1894 con la Compañía General de Tabacos de Filipinas, que tenía una duración prevista hasta la conclusión del arriendo en 1898-1899. Las guerras coloniales dieron al traste con esa política

15 CAT. Actas del Consejo de Administración, sesión del 27 de mayo de 1889. 
de adquisiciones de hoja. Los primeros síntomas del incumplimiento de estos contratos se comenzaron a advertir en 1896 por causa de la guerra de Cuba. La gestión de la CAT se concentró primero en preparar un stock considerable de materia prima, y ya en plena crisis impulsaron la política de sustituciones de las distintas clases de hoja, que desde principios de la década de 1890 se venía desarrollando y encontró un cauce eficaz en ese convulso contexto. Estas sustituciones se centraron tanto en el tabaco en rama como en el tabaco elaborado de importación. Esta política fue beneficiosa para la renta y explica que no se produjera un descalabro productivo sino un incremento notable de las utilidades, situación que se plasmó en el balance efectuado sobre el bienio 1898-1899. Este proceso fue posible porque con antelación se habían estudiado los diversos mercados y las diferentes calidades de hojas, y garantizó de forma aceptable la homogeneidad de los tipos en las labores. El tabaco dominicano y Carmen por sus características suplieron en algunas labores al tabaco filipino. La Compañía General de Tabacos de Filipinas había suministrado 5.550.000 de kilogramos, pero en previsión de que se mantuviese el estado de guerra en el Archipiélago se realizaron compras directas de esta hoja en Alemania, Hungría, Palatinado y Brasil.

La coyuntura de los mercados a fines del XIX impidió mantener el sistema de adquisiciones a través de contratos de larga duración. Liquidados trabajosamente todos aquellos que se habían firmado entre 1894 y 1895, en 1900 la empresa retornó a los contratos a corto plazo, por una o dos cosechas, y a las compras directas de antaño. Sólo se mantuvieron convenios estables con la Compañía General de Tabacos de Filipinas y con el Gremio de Cosecheros de Canarias.

En los meses que transcurrieron entre julio de 1899 y diciembre de 1900 se celebraron contratos para la adquisición de hasta un millón de kilogramos de tabaco de Vuelta Arriba, en Cuba. Y conforme al contrato vigente con la Compañía de Filipinas ésta proporcionó 6 millones de kilogramos. También se mantuvo el convenio firmado en 1897 con la Sociedad anónima Húngara, en virtud del cual ésta suministró 2 millones de kilogramos de tabaco de esa procedencia. En 1901 evaluaba el Consejo de Administración de la Compañía satisfactoriamente la negociación con esa entidad comercial para atender las necesidades de la fabricación en 1901 y 1902 pagándose el kilogramo a 0,62 francos. La adquisición de este tipo de hoja fue oportuna porque en aquellos momentos se carecía de repuesto de

R. I., $1998, \mathrm{n}^{\circ} 213$ 
tabaco Kentucky y no era previsible que pudiera reponerse éste a un buen precio en las cantidades que precisaba la producción. Además, el tabaco húngaro empleado en pequeñas proporciones en las labores daba buenos resultados, especialmente en el picado común suave especial ${ }^{16}$. Además, en 1901 se firmó un contrato con los proveedores de hoja boliche de más de un millón de kilogramos de diversas clases, y por compras directas se obtuvieron más de un millón de kilogramos de tabaco dominicano y tabaco Carmen, respectivamente. En el mercado norteamericano se abrió un concurso para adquirir más de siete millones de kilogramos de tabaco Kentucky pero al resultar excesivos los precios que pedían las casas comerciales (Bondaine y Brower y Abenheim y Cía) se decidió enviar a Francisco Carmona en calidad de Comisionado especial de la casa para adquirir directamente en ese mercado el tabaco que se necesitaba ${ }^{17}$.

En 1899 se habían recibido varias propuestas de las casas comerciales de J. Geerligs (Bremen), Gebrüder Keitel (Hamburgo) y Myrthil Rose y Comp. (París) relativas a suministros de tabaco en rama procedente de Río Grande, lo que fue objeto de un detenido éxamen ya que después de realizar diversos ensayos se consideró prudente emplearlo para mezclarlo con las abundantes existencias que habían de tabacos Carmen y Santo Domingo, cuidando de que no llegase a sustituir el tabaco Brasil que en aquellos momentos entraba en algunas confecciones al 50 por ciento.

Relacionado con esta cuestión se planteó la necesidad de estudiar una reforma en las confecciones de los cigarros, cigarrillos y picados de las clases finas ajustados a las siguientes bases: 1) Para determinar las proporciones de cada confección se debería atender tres aspectos fundamentales; conservar el tipo intrínseco de la labor; contener el aumento de su coste y asegurar que fuese a la par el consu-

\footnotetext{
16 Por otro lado, la Sociedad anónima Húngara se había constituído con una participación del Gobierno de aquel país y adquiría el tabaco de los cosecheros a precios fijados por el Gobierno, siendo, por consiguiente, dicha Sociedad única proveedora del tabaco de Hungría, con lo cual era económicamente improcedente adquirirlo de otras casas europeas, que resultaban a su vez, adquirientes de segunda mano. CAT. Actas del Consejo de Administración, sesión del 27 de junio de 1901.

17 El crédito para esta operación lo concertó la CAT con los banqueros Sres. García Calamarte y Co. de Madrid, por 500.000 dólares. En diciembre de 1900, Carmona había adquirido algo más de dos millones de kilogramos de hoja Virginia y Kentucky, en condiciones ventajosas para la Compañía. CAT. Actas del Consejo de Administración, sesión del 14 de marzo de 1901.
} 
mo de las diversas clases de hojas; 2) a partir de entonces dejaría de invertirse en los cigarros la tripa 1a. de tabaco Carmen y la 2a. de tabaco Sto. Domingo, y en cambio entrarían en su confección el capillo de Sto. Domingo y el Brasil en una mayor proporción, con el propósito de reducir la de filipino; y 3 ) en los cigarrillos y picados se comenzarían a invertir la tripa 1a. del tabaco Carmen y la 2a. de Sto. Domingo, acentuando también la proporción del Brasil, con el mismo objetivo de reducir el tabaco filipino ${ }^{18}$.

En cuanto al tabaco en hoja que componía las labores de picados comunes, fuertes y de hebra y la de los cigarrillos comunes de hebra, se mantuvo la aplicación del tabaco húngaro (intervenía en una proporción de 2/10) ya que, según se registra en las actas "no se habían producido quejas de los consumidores" 19 .

En el laboratorio de la Arrendataria se hacían múltiples ensayos, como los realizados con tabaco en hojas procedente de Bosnia y Herzegovina, que había sido remitido por la Casa de Viena Schcnarda Rotter y Perschitz; tabaco de Ucrania presentado por la Casa de Hamburgo, Carl Cohen y Cía y tabaco de Java que ofrecían las Casas Cremer y Hecren de Amsterdan y la Frowein y Cía de Aruhen, Holanda. De acuerdo con los estudios técnicos, el tabaco de Bosnia era muy parecido al Húngaro que se empleaba en las labores, aunque de calidad algo inferior. El de Ucrania fue desestimado por presentar una fermentación defectuosa y olor penetrante y desagradable y el de Java era susceptible de emplearse para sustituir algunas clases de tabaco de Filipinas, como el Igorrotes $4 \mathrm{a}^{20}$. Esto era importante pues existía una política de sustitución del tabaco Filipino: a mediados de 1900 se aprobó una nueva tarifa de confección del cigarro marca chica en la que se disminuía el tabaco filipinio y entraban en su sustitución los de Java, Sumatra y Carmen ${ }^{21}$.

Eleuterio Delgado Martín estableció como obligatorio el estudio pericial de las muestras de todo tabaco en rama que se ofertaba a la compañía por las diferentes casas comerciales, este dictamen era luego analizado en la comisión industrial que era la encargada de informar a la comisión mercantil para que aprobara o desestimara las

\footnotetext{
18 CAT. Actas de la Comisión Industrial, sesión del 29 de diciembre de 1899.

19 CAT. Actas de la Comisión Industrial, sesión del 9 de marzo de 1900.

20 CAT. Actas de la Comisión Industrial, sesión del 14 de abril de 1900.

21 CAT. Actas de la Comisión Industrial, sesión del 12 de julio de 1900.
}

R. I., $1998, \mathrm{n}^{\circ} 213$ 
adquisiciones en razón de las condiciones de los precios ${ }^{22}$. Y estas nuevas estrategias comerciales rindieron sus frutos. Al dirigirse a los accionistas en marzo de 1903 el presidente del Consejo de Administración de la Compañía señalaba "el sistema de compras directas iniciado en 1900 dió los mejores resultados, en vista de los cuales el Consejo se ha sentido alentado a persistir en él"23.

Continuando la política de diversificación de los suministros, en 1903 comenzó a importarse tabaco en rama del Paraguay, de diversas clases: el capero se destinó a la fábrica de Valencia para emplearlo en la confección de las labores de cigarros Perfectos, Sublimes, Ideales, Deliciosos y Puritanos, que eran los únicos en los que de acuerdo con los ensayos realizados podían aplicarse por el elevado precio de esta hoja. La tripa clasificada como de 1a. y 2a. se invirtió en la confección de cigarros marca chica en la fábrica de Madrid para explorar una probable sustitución del tabaco Carmen, así como la tripa 3a. y las capaduras, pero en los cigarrillos superiores ${ }^{24}$. En 1904 también se importaron muestras de Borneo y Méjico ${ }^{25}$. En agosto de 1905 concluyó el convenio firmado entre la CAT y la Compañía General de Tabacos de Filipinas, entonces se concertó otro, aprobado por Real Orden de 4 de septiembre de 1906 por tiempo indefinido, aunque la CAT se reservaba el derecho de rescindirlo, y en virtud del cual la CGTF acordaba suministrar a las fábricas españolas anualmente 6.778.384 kilogramos de las diversas clases de hoja de aquel archipiélago ${ }^{26}$. Con el resto de los mercados se mantuvo el sistema de compras directas a través de comisionados de la Compañía enviados a estos fines.

En 1907 las compras de tabaco en rama se realizaron todas directamente en los mercados, "insistiéndose en un sistema que ofrece manifiestas ventajas en opinión del Consejo, el cual no por eso desdeña los demás pues entiende que con todos los procedimientos es dable favorecer la Renta, aplicándolos con discreción, oportunidad y celo, y que el utilizar unos u otros ha de depender de las circunstancias, cuya apreciación constituye uno de los cuidados más delicados,

\footnotetext{
22 CAT. Actas de la Comisión Industrial, sesión del 12 de octubre de 1900.

23 CAT. Memoria, Madrid, 1903, p.13.

24 CAT. Actas de la Comisión Industrial, sesión del 21 de enero de 1903.

25 CAT. Memoria, Madrid, 1905, p.11.

26 CAT. Memoria. Madrid, 1907.
} 
complejos y difíciles de la gestión"27. En 1910, por citar un año en que no se registraron irregularidades en las cosechas ${ }^{28}$, las compras de tabaco en rama se efectuaron, como ya era normal, directamente en los mercados, con excepción de Filipinas, adquiriéndose casi 20 millones de kilogramos de las clases siguientes: Vuelta Abajo, Remedios, Canarias, Brasil, Río Grande, Paraguay, Java, Virginia, Kentucky, Maryland, Húngaro y Filipino. En 1911 las adquisiciones de tabaco en rama se verificaron directamente en los mercados, ingresando en los almacenes hasta un total de 17.605.223 kilogramos. De Filipinas, por virtud del convenio estipulado con la Compañía General de Tabacos de dichas islas, ingresaron 9.187.218 kilogramos. En conjunto fue, pues, de 26.792.441 kilogramos la cantidad de tabaco en rama, que recibió la Compañía en el año 1911.

La situación de los suministros se mantuvo controlada hasta el estallido de la primera guerra mundial cuando, en el verano de 1914, se produjo el cierre de mercados importantes como eran el alemán y el holandés y se dislocaron las rutas comerciales tradicionales. La extensión del conflicto al Pacífico, con la declaración de guerra de Japón a Alemania en agosto, complicó aún más el panorama mercantil de la Arrendataria, por las dificultades en el transporte de tabaco filipino a cargo de la Compañía General de Tabacos de Filipinas, que se vió obligada por razones de seguridad a recurrir a la antigua y mucho más costosa ruta del Cabo de Buena Esperanza. Los fletes $^{29}$ y primas de seguro se desorbitaron, este último estaba recargado además con el seguro de guerra. Los mercados europeos se cerraron a toda negociación y se llegó a dificultar notablemente la provisión de la hoja filipina, pero la disponibilidad de tabaco en rama se pudo mantener en proporciones aceptables gracias a los mercados americanos que acusaron una baja en las cotizaciones y pre-

27 CAT. Memorias, Madrid, 1908.

28 En 1907 por ejemplo se dificultaron los suministros de tabaco en hoja por causa de la escasez en las cosechas de Cuba y Brasil que repercutió en un incremento de la demanda del tabaco norteamericano. CAT. Memoria, Madrid, 1908.

29 La gravedad del aumento desorbitado de los fletes estuvo en que se fijaban sobre el peso de éste, con lo que se afectaron sobre todo las clases comunes que justamente no eran susceptibles de asimilar fuertes subidas en los precios de venta. En la Memoria referida al ejercicio de 1918 se señalaba con relación al aumento de los costos " es debido a los enormes fletes que ha habido que satisfacer por el tabaco en rama, fletes que, pagándose por el peso del tabaco, afectan más a las clases comunes que a las finas, en relación con su precio de venta." CAT. Memoria, Madrid, 1919.

R. I., $1998, \mathrm{n}^{\circ} 213$ 
sentaron, además, cambios favorables, lo que compensó en alguna medida los aumentos en otros gastos ocasionados por el conflicto ${ }^{30}$.

Las mayores dificultades se produjeron con las provisiones de tabaco filipino. Desde septiembre de $1914^{31}$ comenzó un seguimiento mensual por la comisión industrial sobre la disponibilidad de tabaco de esa procedencia por clases, en los almacenes y fábricas españolas, y aunque al finalizar ese año existían sobrantes en todas las marcas previstas en el contrato, el 5 de noviembre el consejo de administración acordó, en previsión de mayores complicaciones, aceptar todas las cantidades de tabaco que pudiese trasladar la Compañía General de Tabacos de Filipinas en concepto de anticipo, dadas las circunstancias vigentes ${ }^{32}$. Pero el 16 de diciembre de 1914 la comisión de fabricación, teniendo en cuenta la perturbación que en las ventas había producido la elevación de precios de las labores, y las irregularidades previsibles por causa del conflicto europeo ${ }^{33}$, propuso la conveniencia de fijar el suministro anual en 7.020.000 kilogramos, o sea 158.850 kilogramos más que los que se encontraban estipulados con anterioridad ${ }^{34}$, todo lo cual fue aprobado por el consejo de administración de la Compañía el 22 de diciembre ${ }^{35}$.

En marzo de 1916, y en cumplimiento de la Real Orden de 24 de mayo de $1915^{36}$, la Arrendataria acordó abonar el aumento del flete para los bultos de tabaco procedentes de aquellas islas fijado por la

30 CAT. Memoria, Madrid, 1916.

31 CAT. Actas de la Comisión Mercantil, sesiones del 24 de septiembre, 26 de noviembre y 24 de diciembre de 1914.

32 CAT. Actas del Consejo de Administración, sesión del 5 de noviembre de 1914.

33 Todos esos factores inevitablemente trastornaron la situación de los repuestos, ocasionando excesos en unas clases y faltas en otras.

34 Estas nuevas consignaciones comprendían: Isabela 1a. 12.000 kilogramos; Isabela 2a. 128.000 kilogramos; Isabela 3a. 600.000 kilogramos; Isabela 4a. 2.300.000 kilogramos; Cagayán 2a. 100.000 kilogramos; Cagayán 3a. 130.000 kilogramos; Cagayán 4a. 600.000 kilogramos; Visayas 2a. 1.000.000 kilogramos; Igorrotes 3a. 350.000 kilogramos; Igorrotes 4a. 2.500.000 kilogramos. CAT. Actas de la Comisión Industrial, sesión del 16 de diciembre de 1915.

35 CAT. Actas del Consejo de Administración, sesión del 22 de diciembre de 1915.

36 Esa Real Orden aprobó la renovación del contrato vigente entre la Arrendataria y la CGTF en virtud del cual se estipuló que " serán de cargo de la Renta los aumentos de gasto que sufra la conducción marítima del tabaco debidos exclusivamente a causas extraordinarias, de guerra u otras, que afectan a la navegación en general, siempre que se justifiquen debidamente estas causas y dichos aumentos a juicio de la Compañía Arrendataria con la Representación del estado cerca de la misma". CAT. Actas de la Comisión Industrial, sesión del 30 de noviembre de 1916. 
Compañía Trasatlántica a la CGTF a causa del alza que habían tenido los gastos de navegación desde enero de 1916 (seguros, carbón, aceites, grasas, víveres). Éste consistió en 697 diezmilésimas de peseta el kilogramo de tabaco, lo que representaba un incremento del 50 por 100 sobre los tipos anteriores ${ }^{37}$. En octubre se produjo un nuevo aumento de 315 diezmilésimas ${ }^{38}$. El 20 de abril de 1917 acordó la comisión industrial proponer al consejo de administración que accediese a la solicitud de la Compañía General de Tabacos de Filipinas de aumentar en un 30 por ciento los precios de todas las clases de tabaco en rama comprendidas en el contrato ${ }^{39}$. En junio de 1917 la gerencia de la CAT apoyó las gestiones que realizaba la CGTF encaminadas a fletar algún buque de bandera neutral para agilizar el transporte de tabaco filipino; vapor que cobraría a razón de 132 pesetas por la conducción de cada 100 kilogramos ${ }^{40}$. Como era de suponer, la demanda de la cosecha de tabaco filipino de 1918 fue seguida de un alza de precios excepcional en aquel mercado, que obligó a la CGTF a realizar un fuerte desembolso para no quedarse sin existencias en 1919. Todo lo cual redundó en un nuevo reajuste de los precios concertados con la CAT que fueron aprobados el 12 de septiembre de 1918 a la vista de un año ${ }^{41}$. Hasta 1916 la disponibilidad de hoja filipina fue adecuada para las necesidades de la fabricación. Los débitos se comenzaron a notar en 1917 con el tabaco en rama de Igorrotes y el período más crítico fue entre los meses de octubre y marzo de 1918, hasta que en diciembre la situación comenzó a normalizarse ${ }^{42}$.

En este sentido, la dirección de la Arrendataria expresaba a sus accionistas al referirse a la gestión desarrollada en 1918, que " Nun-

37 CAT. Actas de la Comisión Industrial, sesión del 2 de marzo de 1916.

38 La situación del transporte era tan crítica que estos excesos en los fletes se consideraban "moderado" ya que en la misma fecha equivalían la mitad del que abonaba la Compañía de Filipinas a las Mensajerías Francesas para sus suministros de tabaco a la Regie. CAT. Actas de la Comisión Industrial, sesión del 30 de noviembre de 1916.

39 CAT. Actas de la Comisión Industrial, sesión del 26 de abril de 1917.

40 CAT. Actas de la Comisión Industrial, sesión del 23 de junio de 1917.

41 CAT. Actas de la Comisión Industrial, sesión de 12 de septiembre de 1918.

42 CAT. Actas de la Comisión Industrial, sesiones de 25 de marzo, 29 de abril, 27 de mayo, 24 de junio, 22 de julio, 26 de agosto, y 23 de septiembre de 1915; 3 de febrero, 24 de febrero, 23 de marzo, 27 de abril, 31 de mayo, y 28 de septiembre de 1916; 4 de enero, 1 de febrero, 29 de marzo, 20 de abril, 24 de mayo, 5 de junio, 15 de julio, 23 de agosto, 18 de octubre, 27 de noviembre, 28 de diciembre de 1917. Referencias de las disponibilidades de tabaco en rama filipino a todo lo largo de 1918 con excepción del mes de abril. 
ca, como en el último período de la guerra, se sintieron en nuestro país sus funestos efectos; nunca fue mayor el encarecimineto para las adquisiciones y los transportes, la elevación casi inverosímil de los fletes y el desquiciamiento de todo cálculo y previsión posibles"43. La adquisición de la hoja se logró sobre la base de la elevación de los precios durante la primera guerra mundial. Con relación a la provisión del tabaco filipino, la Arrendataria continuó facilitando a la Compañía General el cumplimiento de sus compromisos y al determinarse la novena anualidad del contrato (que cubría los meses comprendidos entre el 1 de septiembre de 1918 al 3 de agosto de 1919) se estipuló un recargo sobre los precios de aquel, que fue aprobado por Real orden del 9 de diciembre de 1918. El resto del tabaco en rama se obtuvo a través de compras directas en los mercados de origen, siendo el conjunto de las adquisiciones en 1918 de 21.897.032,359 kilogramos ${ }^{44}$.

At the time when the Spanish State handed over the management of the tobacco monopoly to a private enterprise -and the Compañia Arrendataria de Tabaco (Tobacco Leaseholder Co.) was created - the Philippine market played a relevant role in the supply of both leaves and manufactured products. However, that modification entailed changes in the norms governing the changes undergone and the establishment of a new commercial policy that laid down rules for the relationship between the Compañia Arrendataria de Tabaco and the Philippine General Tobacco Co.

43 CAT. Memoria, Madrid, 1919, p.6.

44 Lo que no obstante resultó insuficiente ya que se tuvo que realizar un serio esfuerzo " para lograr que se mantuvieran los repuestos bastantes para evitar el riesgo de una paralización en la producción.” CAT. Memoria, Madrid, 1919, p.7. 